\title{
Chaos as Dialectic: Stanislaw Lem and the Space of Writing
}

Canislaw Lem has a formidable range of interests. Trained as a himself cybernetics, possesses a good working knowledge of biology, knows quite a lot about cosmology, has read extensively in critical theory and philosophy, and writes in Polish, German, and English. The one thing he seems not to know is chaos theory-at least not in the explicit forms discussed earlier, in which chaos is identified with a new set of paradigms. When Lem writes about chaos, he understands it in the older sense of chance, randomness, disorder. Through his reading in cybernetics, he has had ample opportunity to learn about the principle of self-organization that underlies Prigogine's work. However, he has not published anything to date that would indicate he has read Prigogine or knows about applications of the idea of self-organization to chaotic systems.

Yet chaos is a topic of almost obsessive interest for Lem. His writing suggests that he considers accounting for randomness and disorder perhaps the most important issue in twentieth-century thought. Influenced both by his scientific training and by poststructuralism, he is concerned with the interaction between something and nothing as they collaborate to form human meanings. His fascination with disorder, his wide reading in cybernetics, and the influence of post- 
modern fiction and literary theory have led him to an idiosyncratic blending of some of the same elements that are evident in chaos theory, although the patterns he weaves and the conclusions he draws are uniquely his own. In a sense, he partakes of the foment that led to chaos theory without participating in the paradigm.

Whereas chaos theory identifies a new kind of orderly disorder, Lem sees order and disorder as bound together in a dialectic that enfolds them into each other while still permitting each to retain its distinct identity. Where Prigogine sees the void as a fecund space of creation, Lem envisions it as interpenetrating the apparent fullness of the world, rendering signification problematic and certainty impossible. When Lem's work is seen in the context of chaos theory, it suggests that when certain concepts become highly charged, they will appear in various combinations throughout the culture, not only in the authorized versions that crystallize around new paradigms.

Few writers speak as much about their own and others' works as Lem. His interviews, personal essays, critiques of science fiction, philosophical treatises on language, and sweeping attempts to categorize modern fiction testify to his continuing fascination with the processes and products of writing. In this writing about writing, there is a curious division between process and product-between the way Lem talks about the creation of texts and the way he thinks about fictional works, including his own, once they have been written. Many writers experience a split between the creator and the censor, the intuitive self who experiences writing as subjective creation and the analytical self who stands back from what has been written to revise and reshape the material. But for Lem the division is more radical; creator and censor do not operate within the same space. This does not mean, however, that the dialectic between them is unimportant. It is invisible precisely because it is so important. Displaced from direct articulation, it is the ground from which articulation emerges.

The ratiocinative side of the dialectic is most apparent in Lem's critiques of modern fiction, especially science fiction. Typically he summarizes the plot, identifies the basic ideas, and then shows that they are self-contradictory or incompatible with known facts. The inevitable conclusion is that the work is "twaddle" because it does 
not satisfy these demands.' Although most of these critiques are directed at the work of other authors, his own books are not exempt from scrutiny. He has repeatedly dismissed his early works as flawed or "purely secondary" because the ideas they embody seem to him deficient (1984:93). From such analyses, one might well conclude that for Lem, the cognitive structure of a work is the work.

His speculations on the theoretical possibilities open to contemporary writers do nothing to dispel this impression. The strategy he follows in "Metafantasia: The Possibilities of Science Fiction" ( $198 \mathrm{I}$ ) is typical. First he gives examples of various kinds of ideas a writer might use as a basis for a story. Then he criticizes the ideas according to their value as rational hypotheses, implying that the bolder and more consistent the hypothesis, the better the work that embodies it. Since it is easy to recognize among these "hypothetical" possibilities ones that he has in fact used in various fictions, it is tempting to conclude that when he writes, he begins with an idea that has been carefully thought out and tested for rational consistency and then proceeds to invent fictional situations that will work out its implications.

According to his own testimony, however, this is far from the case. "Nothing I've ever written," he states, "was planned in an abstract form right from the start, to be embodied later in literary form." " Moreover, the works that had relatively more planning he regards as his worst, novels that he acknowledges as his own "only with some discomfort". With the books that he believes are successful, he confesses to have "found [himself], during the writing process, in the position of a reader," as uncertain about what would happen next as if someone else were the author. "Considering myself to be a rationalist, I dislike such confessions," he admits; "I should prefer to be able to say that I knew everything I was doingor, at least, a good deal of it-beforehand" (I 984:94).

The division between his intuitive method of writing and the analytical rigor of his writing about writing has deep roots in his past.

\footnotetext{
'Lem, 1971a:322. See also Lem, 1974a.

${ }^{2}$ For further testimony on Lem's wariness about planning his works in advance, see Istvan Csicsery-Ronay's "Twenty-two Answers and Two Postscripts: An Interview with Stanislaw Lem," Science-Fiction Studies I 3 (November 1986): 242-260.
} 
In an autobiographical essay titled "Chance and Order" (1984) he speaks of the radical break that occurred in his life when his privileged and secure childhood in the Ukraine was disrupted by the cataclysmic upheavals of World War II. His life broke in two. On one side was a childhood in which he "lacked nothing," indulged by a "respected and rather wealthy" father (p. 88); on the other side was his life during and after the war, in which he "resembled a hunted animal more than a thinking human being" (p. 90). In the first period, life was stable, rational, predictable, but isolated within the closed structure of a family whose affluence made it an enclave within an impoverished and threatened country; after the break, life was unstable, irrational, and unpredictable, but open to the excitement of the streets and the dangers of chance. "I was able to learn from hard experience that the difference between life and death depended upon minuscule, seemingly unimportant things and the smallest of decisions: whether one chose this or that street for going to work ... whether one found a door open or closed" (p. 90). The image of the open door is significant. His response was not to minimize danger but, in some instances, to court it. He recounts incidents when he deliberately exposed himself to risk, as if to test his ability to survive in a world of chance.

The relation of these experiences to his divided response toward writing was apparently forged during the transition between the two phases. Recalling his earliest writing, in which he would "transport [himself] into fictitious worlds," he emphasizes that he did not "invent or imagine them in a direct way. Rather, I fabricated masses of important documents when I was in high school in Lvov: certificates; passports; diplomas ... permits and coded proofs and cryptograms testifying to the highest rank-all in some other place, in a country not to be found on any map." Wondering if he invented these documents to assuage an "unconscious feeling of danger," he concludes that "I know nothing of any such cause." Yet the fact remains that at this critical juncture, when the order of his early life was threatened by events beyond his control, he turned to the invention of texts as a way to create a space that would be open to uncertainty and danger, but within which he would be protected by the "full power of authority." It is no exaggeration to say, as he does, that the two opposed principles of chance and order "guide my pen" 
(p. 88). Indeed, one might conclude that it is this dialectic that put the pen into his hand. ${ }^{3}$

For Lem, writing creates a mediating space in which openness and closure, chaos and order, creation and ratiocination engage each other in a self-renewing and multilayered dialectic. When writing is in progress, the emphasis is on the open-endedness of the processanything may happen, infinite possibilities lie open to the creator, chance fluctuations create situations whose outcomes cannot be foreseen. But this openness also undermines authority, putting the writer "in the position of a reader," subject to vicissitudes he cannot control ( $1984: 94)$. He can reassert order by writing about writing, creating documents whose purpose is not primarily creation but regulation (recall the passports, diplomas, certificates that were among Lem's earliest creations). In this writing about writing, possibilities are enumerated only to be evaluated by the rational faculty and, as often as not, dismissed. Because writing about writing unfolds in a separate space from writing as such, the dialectic that engages the creative and ratiocinative self is displaced from direct articulation. On this level, there appears to be simply a dichotomy, rather than a dialectic, between the two modes.

The dialectic begins to come into sight when we view both the writing and the writing about writing as, after all, writing. When writing is ongoing, it creates an open space rich with latent, unarticulated possibilities. Yet writing, especially successful writing, produces products-pages, drafts, texts, books. Once these products exist, the space has been closed, the order of the words stabilized. How to maintain the tension between chance and order which is for Lem the condition of writing, even though the writing itself has ceased? In his writing about writing, he suggests a host of possibilities-for example, interspersing random "noise" throughout the text so that one can never be sure what is message, what chance. "If we posit that the task of literature is not to ever give a definitive explanation of what it presents, and is therefore to affirm the autonomy of cer-

\footnotetext{
${ }^{3}$ The conjunction of World War II and Lem's fascination with chance suggests that the upheavals of World War II may have been important factors in focusing the attention of that generation on chance. The war effort was intimately bound up with the development of information theory, which was created in part to control chance situations.
} 
tain enigmas rather than to enter into explanations, then the most engimatic of possible secrets is a purely random series" (I98I:65). Here the value of chaos for Lem becomes clear; it allows literature to elude criticism's attempt to close the space of writing. Yet in another sense, in this passage he is in fact attempting the "definitive explanation" that he hopes chaos can defeat. Driven or led to ratiocination, he yearns to create a chaos that can defeat explanation; faced with chaos, he cannot resist entering into explanations. The effect of these convoluted crossings within the space of writing is to create a dialectic that ceaselessly renews itself, wresting rational explanations from the enigmatic silence of the text even as it opens fissures within the text which subvert those same explanations. ${ }^{4}$

In Lem's view, the dialectic between chaos and order occupies a central place in all writing. Far from seeing it as an idiosyncrasy peculiar to him, he believes it is intrinsic to language. On the one hand, language is "the instrument of description," operating to bring order and stability to perception; on the other hand, it is "also the creator of what it describes," caught in a self-referential loop whose lack of ground leads to radical indeterminacy (1981:62). Lem is of course not alone in emphasizing the self-referentiality of language. Julia Kristeva sums up the spirit of a generation when she writes about the "theoretical ebullience" of criticism following its "discovery of the determinative role of language in all human sciences" (1980:vii). Yet there are important differences between poststructuralists such as Kristeva and Lem's version of that "theoretical ebullience." While he would agree with Kristeva about the importance of language in the construction of culture, he is also interested in informational markers that distinguish between description and creation. He believes, in other words, that language can be referential as well as self-referential. Because creation through language is for him a double act, transforming stochastic process into ordered text and textual order into chance events, his writing has affinities with poststructuralism but is perhaps distinct from it in its insistence on the continuing tension inherent in the dialectic. Acknowledging the void, he also posits a "somethingness" that remains apart from the postmodern vacuum.

${ }^{4}$ Frank Occhiogrosso, 1980, discusses Lem's The Investigation as an example of a permanent enigma. 
In addition to his view that language "always has meanings oriented toward the world of real objects" ( 1973 b:26), Lem is distinguished from other poststructuralists by his belief that literature must be about something other than textuality if it is to engage ethical questions. The disappearance of "conventional structures of ethical judgment all over the planet" is in his view profoundly bound up with the kind of space in which the modern writer works (I98I:6I). In "Metafantasia" he argues that the energy for literary creation has historically come from the writer's resistance to conventional ethics. If there are no conventional ethics, the writer faces a very different kind of problem: he or she must then create out of a void. The erosion of traditional values has turned the writer's task on its head. The contemporary writer must invent, as well as overcome, the resistances on which writing depends. He must (like Lem) conceive of writing as a double act, at once introducing the constraints that will carve a defined space out of the void and opening fissures within it which will protect the space from oppressive closure.

The metaphoric interplay between enclosed and open spaces is thus central to Lem's thought, whether the subject is culture, ethics, or language. ${ }^{5}$ The project of his writing is to define a space that is neither full nor void, excessively cluttered nor empty, because these extremes threaten to destroy writing. Nevertheless, it is only by articulating the extremes that one can create the space of writing, for they are the boundaries that delineate it. In the face of this double jeopardy, Lem's characteristic response is to turn the extremes back on themselves. By enfolding openness into closure, chance into necessity, excessive information into empty language, his writing creates a space that seems to exist apart from the boundaries that bring it into existence. Without the dialectic the space of writing as he envisions it could not exist, for in a very real sense the dialectic is that space. The words on the page are the visible trace that the dialectic leaves behind. But for him the dialectic "guid[ing his] pen" is writing-in-itself.

The operation of the dialectic can be illustrated through two representative works, The Cyberiad (1974b) and His Master's Voice

5erzy Jarzebski also comments on the marked division between Lem's rationalism and his "special inclination for phantasmagoric visions," a dichotomy that Jarzebski suggests can be modeled through "open and closed space" (r977:123). I am indebted throughout this chapter to Jarzebski's insights. 


\section{22 Something out of Nothing}

(1983). The Cyberiad is a collection of cybernetic fairy tales written in a grotesque mode. His Master's Voice is a psychologically realistic novel that is arguably the best of Lem's serious fiction. Operating within different generic conventions, the two texts are not so much opposites as mirror reflections of each other. The same dialectic is at work in both, although it proceeds in opposite directions.

Consider first The Cyberiad. The stories in this collection are noteworthy for their absence of a reality principle. Any idea, no matter how absurd, can be used if it can be put into words. How does one materialize a dragon? By amplifying its probability. How does one answer ultimate questions about the meaning of life? By building a Gnostotron that knows everything. Creation takes place because the appropriate words exist or can be invented, not because objects to which the words refer exist. In view of this linguistic zaniness, it is hardly surprising that the central problem in The Cyberiad is how to create something from nothing. When everything is possible, the urgency of generating internal constraints is especially pressing.

His Master's Voice, by contrast, unfolds as the autobiography (or "antibiography") of the preeminent mathematician Peter Hogarth. As its foregrounding of science suggests, His Master's Voice has a much firmer internal reality principle than The Cyberiad. Along with this difference in initial assumptions goes a corresponding difference in goals. Characters in His Master's Voice are concerned not with creating from the void but with determining the status of something that has emerged from the void. This is one of the cases where Lem's "hypothetical" suggestions "retrodict" books he has already written, for the neutrino transmission (the voice of the title) is so densely coded with information that it is virtually indistinguishable from noise. For the characters as well as the reader, the transmission represents a permanent enigma (about which Lem had speculated in "Metafantasia"). As a result, the claustrophobic enclosures of the text are opened to radical uncertainty. ${ }^{6}$

It is now possible to see how the two texts reflect and invert each

'Jarzebski (1977: 1 22) comments on how marked Lem's work as a whole is with a sense of claustrophobia, "by the suspicion that the apparently limitless universe surrounding us is in reality a huge, misleading stage backdrop designed to fit our cogni- 
other's assumptions in the mirror relation of their dialectics. The emptiness of The Cyberiad is introduced as a premise, an absence of originary essence, whereas the emptiness of His Master's Voice is presented as a conclusion, a result of informational excess. The Cyberiad foregrounds the emergence of its language from the void, emphasizing its creation ex nibilo. It then introduces successive constraints until ethical judgment finally becomes possible. His Master's Voice, by contrast, appears initially to validate its language as a referential symbol system, locating its subject in reality rather than in language. But this referentiality is decentered by the neutrino transmission, whose excessive signification gives rise to multiple (and multiplying) interpretations. At first ethical judgment seems clearcut, even complacent. But by the end, judgment has been so contaminated by hermeneutics that it is only by an act of faith that the narrator can achieve any kind of closure at all. Beginning at opposite ends of the open/closed spectrum, the dialectics meet in the middle. Whether the text begins with order or chance, referentiality or selfreferentiality, by the end both polarities have been so enfolded into each other through the operation of the dialectic that they are inextricable.

Reinforcing this mirror relation are different stances toward the language that creates and the language that describes. The Cyberiad introduces semantic markers that distinguish between descriptive and creative language by introducing a complex set of narrative/ frame distinctions. As its narrative structure grows increasingly hierarchical, ethical judgment emerges through implicit connections between different narrative levels.' In His Master's Voice, the basis for ethical judgment is articulated at the beginning but becomes progressively more ambiguous as the narrator's descriptions of his life, scientific work, and colleagues engage each other in circular reasoning that makes it impossible to contain cause and effect within a logical hierarchy. Whereas in the grotesque work ethical judgment

tive faculties, while the essence of things is hidden away somewhere else, behind the stage." When queried about the Jarzebski comment in the Csicsery-Ronay interview, (see n. 3), Lem replied, "As for claustrophobia, I don't feel any . . . but I can conjure an aura of claustrophobia or agoraphobia, if needed, in my writing." Whatever Lem's personal psychology, claustrophobia is a prominent feeling in his writing.

${ }^{7}$ For a different view, see John Rothfork, 1977. 


\section{24 Something out of Nothing}

emerges through the introduction of formal structure, in the serious novel it grows more problematic as the initial regulating structures prove insufficient to order the text. By the end of both texts, the paradoxical configuration of the textual space renders ethical judgment both inescapable and irreducibly complex.

The dialectic is already in operation at the beginning of The Cyberiad, when Trurl creates a machine that can make anything that starts with $n$. To test it, Klapaucius asks it to make Nothing, whereupon the machine starts unmaking the world. This opening story demonstrates how Lem's dialectic simultaneously invents constraints and deconstructs them. In construing "Nothing" as a substantive noun that has positive being-in-the-world rather than negation describing a lack of being, the creation machine performs a linguistic sleight-of-hand that transforms the void into the full. At the same time, to create this fullness the machine must deconstruct everything in the world, thus turning it into a void. By enfolding the void and the full into each other, this opening story creates through writing the space of writing.

Central to this paradoxical enfolding is the balance between creation and destruction. To prove it can make anything that starts with $n$, the machine must continue to make Nothing until it finally deconstructs everything, including the constructors and itself. Fortunately, the constructors are able to deflect it from this course of uncreation before deconstruction is complete. Some things still exist, although the world remains "honeycombed with nothingness" (1974b:8). The machine has operated long enough, however, to undermine the referentiality of language. For those objects it has deconstructed, only names remain to signify the resulting voids. "The gruncheons, the targalisks, the shupops, the calinatifacts, the thists" have all disappeared as objects in the world and remain only as signs within the text (p. 6). The ontological security of realism has thus been undercut, since language is revealed as an instrument of uncreation as well as of creation. However, to deconstruct everything would be self-defeating, not least because for Lem creation depends on a dialectic between something and nothing. If there were only the void, creation would be impossible. In this just-so story explaining how the world came to be as it is, the partly deconstructed universe resembles a Swiss cheese, for within the heavens dotted with stars 
gape holes left by the annihilated "worches and zits." The universe has become the space of writing, containing both self-reflexivity and representation in its paradoxical configuration.

Within the space opened by this initial writing the rest of the text unfolds, evolving through a continuing textual interplay between emptiness and excessiveness. In the story of the Multitudians, for example, Lem imagines a culture in which numerosity is everything. Only masses are valued, not single beings. The uses to which the King of the Multitudians puts his subjects are significant. In an attempt to prove to Trurl the delights of numerosity, the King points out that his subjects can literally be made into signs-living mosaics "providing sentiments for every occasion" (I974b: I 80-I 8I). Trurl, unimpressed, thinks to himself that "an overabundance of thinking beings is a dangerous thing, if it reduces them to the status of sand" (p. I 80). The King's suggestion that his subjects can be used rather like Hallmark greeting cards links excessive numbers to a textuality that empties the subject of its traditional humanistic content. In Lem's view, if language is empty, it cannot be used to express ethical concerns. If the subject is empty, it cannot be used as a locus of value. The planet of the Multitudians thus presents to the constructor the same erosion of traditional values that Lem sees as characteristic of the modern era. ${ }^{8}$

For Trurl, the problem is more practical than philosophical. Although he dislikes the King's ethics, he dislikes still more his suggestion that Trurl accept "two or three hundred thousand" of his subjects as recompense for creating a Perfect Adviser (p. ı 80). Trurl insists on gold, and the King reluctantly agrees. When the King later attempts to defraud Trurl of his rightful payment, Trurl devises a stratagem to make the King fall victim to the very superfluity of signs that he tried to urge on Trurl. The stratagem is simplicity itself. Trurl sends an innocuous letter to the Adviser, knowing that the suspicious King will believe the letter is written in code. Because there is no code, there are no constraints limiting interpretation, and the King's experts generate more and more possible messages from

\footnotetext{
${ }^{8}$ Rothfork (I98I), discussing the ethical implications of "having everything," places Lem's view of superfluity in the context of utilitarianism.
} 


\section{26 Something out of Nothing}

the letter. The King, having ignored ethical constraints in turning his subjects into signs, is now confronted by a textual void opened by the lack of constraints within Trurl's letter.

Determined to arrive at a unitary meaning, the King calls in the world's "greatest expert in secret writing," Professor Crusticus. The professor, the "distinguished discoverer of invisible sign language," assures the King that he can find the text's one true meaning. He discovers that if he "added up all the letters of the letter, subtracted the parallax of the sun plus the annual production of umbrellas, and then took the cube root of the remainder," he would have the answer. The King's agents confirm the professor's solution by torturing the unfortunate citizen whose name is an anagram of it (p. I9I). What the professor's solution exposes is not, of course, the putative answer that the King seeks, but a moral of which the King remains oblivious, although it is clear enough to the reader. Theories about language which claim that it is free to be interpreted in any way whatsoever are the allies and precursors of state terrorism.

The connection between the textual politics of empty language and political violence is underscored when Trurl too is ensnared within the proliferating signs. By encoding the Adviser's program with his own wisdom, Trurl is put in the difficult position of "attempting to conquer himself, for the Adviser was, in a sense, a part of him" (pp. I87-I88). Trurl is vulnerable to even such an oaf as the King because he has reduced his identity to a series of signs and replicated them within the Adviser. If identity is merely a collection of signs, capable of dissemination through multiple cybernetic texts (a possibility explored at length in "The Mischief of King Balerion," another story in The Cyberiad), then on what basis can human rights, which rest on the sanctity and uniqueness of the individual, be justified? The question is at the center of this text, as it attempts to construct spaces in which the chaotic superfluities of disseminating acts and words are balanced against the oppressively closed structures of tyranny. When the balance shifts too far in either direction, the results are invariably disastrous.

The potential for violence that opening identity to dissemination can unleash is brought forcibly home for Trurl in "A Good Shellacking." In this story, Trurl attempts to trick his fellow constructor, Klapaucius, by passing himself off as "a Trurl," a copy of himself 
which his marvelous "Machine to Grant Every Wish" has created. Taking the "copy" at its word, Klapaucius locks it in the basement and starts to beat it. Trurl howls in protest, but Klapaucius insists that he has every right to use Trurl as he pleases, since he is only a copy, not the real Trurl. Finally Trurl escapes and, when Klapaucius calls the next day, tells him that he was forced to dismantle the false Trurl because it defamed his good friend Klapaucius. The shrewd Klapaucius knows perfectly well, of course, that there never was a copy. What Trurl has dismantled is a sign, not a physical object.

When the copy is a cybernetic organism rather than a sign, the problems caused by proliferating identities are not so easily solved. Significantly, when Lem's characters are confronted with the perplexing issue of distinguishing between an original and a created self, they often find themselves unable to impose any ethical solution upon the situation. In "How Trurl's Perfection Led to No Good," for example, Trurl creates a miniature kingdom in a box and peoples it with tiny beings as a toy for the tyrant Excelsius. When Trurl returns home, Klapaucius points out to him with horror that because the creatures Trurl has made are in every way indistinguishable from real beings, they are real: a "sufferer is one who behaves like a sufferer" (p. I69). Because of Trurl, living creatures who are trapped within the box are entirely at the mercy of Excelsius. Meaning only to placate Excelsius, Trurl has condemned them to a living hell. Creating the box was clearly a mistake; how to correct the error? Destroy the box? Professor Dobbs, encountering similar difficulties in "Non Servium" (in A Perfect Vacuum, I97 Ib), finally decides that he has no ethical options. The best he can do is to delay for as long as possible throwing the switch that will kill his artificial beings.

Trurl's dilemma has a happier outcome, for when he returns to the kingdom-in-a-box, he finds that the miniature beings have escaped their enclosure and turned the tables on their tyrannical ruler, exiling Excelsius to the void. Clearly a startling reversal has taken place, for one of the text's most claustrophobic and tyrannically oppressive enclosures has been opened, while the tyrant has been transformed into a rather picturesque moon. How did this marvel occur? Although no explicit explanation is given, there are hints that it comes about because the inhabitants of the box are capable of self- 
organizing processes. If ethical solutions cannot be imposed from without, perhaps they can arise from within.

This conclusion paves the way for the reemergence of ethics from the space of writing. While the stories have been showing various kinds of self-organizing processes in action within the narratives, the narrative space itself has grown increasingly complex and hence susceptible to self-organization in its own right. In Lem's view, literature-indeed, language itself-is engaged in a feedback loop in which articulating an idea changes the context, and changing the context affects the way the idea is understood, which in its turn leads to another idea, so that text and context evolve together in a constantly modulating interaction. Regulating structures provide a way to control this interaction and use it constructively.

In general, the hierarchical structures characteristic of self-regulating systems evolve because they are necessary, and they are necessary because they introduce the constraints that bring feedback loops under control by partially "insulating" the changes going on at one level from those at another. How these self-organizing processes occur is illustrated through the increasing complexity of The Cyberiad's narrative structure. From the first story on, feedback loops are created which enfold the narrative space into itself. Consequently, as the stories progress, the space becomes more and more convoluted. By the "King Genius" story, no fewer than three distinct narrative frames are employed, with as many as fifteen stories nested inside a single frame. The structure implies that the narrative/frame hierarchies must be this complex to control the proliferating narratives. At the same time, the greater complexity leads to the possibility of multiple interactions between levels, so that the space is opened to narrative proliferation again. As chaos leads to order, and order back to chaos, the narrative comes to resemble an organism that grows by periodically dissolving and reassembling, each time at a higher level of complexity. In this sense the narrative is a cybernetic organism, manifesting within itself the same self-organizing processes that the stories take as their subject. ${ }^{9}$

It is this self-organization that allows ethical judgment to be in-

"For a subtle analysis of how Lem's novels in general become "cybernetic," see Robert M. Philmus, 1986. 
trinsic to the space of writing, emerging from within rather than imposed from without. As the text undergoes periodic deconstruction and reassembly, the feedback loops that originated the self-organizing processes work to increase ethical awareness. In one of the "King Genius" stories, for example, we are told about a book by Chlorian Theoreticus the Proph titled The Evolution of Reason as a Two-Cycle Phenomenon. According to the Proph, robots and humans are joined by a "reciprocal bond" of mutual creation ( $p$. 244). First humans evolve and create robots. In time the humans die out, and the Automatas, "having freed themselves from the Albuminids, eventually conduct experiments to see if consciousness can subsist" in protein (p. 245). So the robots create "synthetic palefaces," who in turn eventually again make robots. Because the two phases are bound together by a continually evolving feedback loop, neither human nor robot can logically claim to be "original." Conversely, neither one is merely a copy to be used for another's pleasure. The scenario implies that in a cybernetic age, although neither silicon mechanism nor protoplasmic organism has priority, both have rights. The feedback loops that configure the space of writing thus also serve as a model for ethical awareness.

So complex are the multiple interactions between stories and between different narrative levels within the same story that it would take hundreds of pages to explicate fully the connections between ethics and language which emerge in this little book. As an example of this complexity, consider the "Doctrine of Inaction," first proposed by King Genius, the auditor of Trurl's stories. Reasoning that if one cannot control all of the consequences of one's actions, it is better not to act at all, King Genius has abdicated his throne and fallen into a deep depression from which only the most entertaining stories can rouse him. In this context, the Doctrine of Inaction appears as moral paralysis. "Inaction is certain, and that is all it has to recommend it," Trurl admonishes the King. Unlike the King, Trurl favors action precisely because it is uncertain. "Therein lies its fascination," he asserts (p. 177). Trurl's judgment is not the last word on the subject, however, as the subsequent story "Altruizine" makes clear. In a different context, the uncertainty of proliferating actions can be more devastating than the certainty of doing nothing.

In "Altruizine," Klapaucius moves out of the King Genius frame 
to continue his quest for the perfect action inside another story told by Bonhominus to Trurl. Bonhominus recounts how Klapaucius is given altruizine by HPLDs, the beings who represent the Highest Possible Level of Development. The HPLDs have been convinced, through long and unhappy experience, that the only sound policy is the Doctrine of Inaction. Consequently, they present altruizine to Klapaucius by way of an object lesson. The drug has the peculiar property of causing everyone to feel what everyone else in the immediate vicinity is experiencing. Klapaucius presents it in turn to Bonhominus, who is convinced that he can use it to solve the world's ethical problems. He subsequently dumps it in a town's water supply. Without the controlling constraints imposed by hierarchical structures, the feedback loops that the drug initiates quickly spiral out of control. A man has a toothache, for example, and his neighbor runs screaming into the street. The chaos that Bonhominus unleashes is linked through the feedback image with the relatively simple narrative/frame structure that this story employs. The implication is that ethical judgments appropriate to the convoluted space of "King Genius" may not be appropriate to a space that is less complex and hierarchical. The way the space of writing is configured is thus intimately bound up with the kind of ethical judgments that are appropriate within it.

The "something" that emerges from the void in The Cyberiad is not, then, a general rule of conduct, but a dialectic that circles back on itself to raise the level of ethical awareness, slowly and often painfully. That there finally are no definitive answers is a foregone conclusion, given the complexity and diversity of the ethical questions that are posed. There are, however, correlations and symmetries that reveal how language and ethics are interrelated. Ethical awareness for Lem means being aware of these relations. By enfolding the full into the void, openness into closure, the dialectic has caused ethical awareness to reemerge from the vacuum of a deconstructed world.

His Master's Voice is like The Cyberiad in its refusal to validate ethical standards that hold true for any time, any place. The void that this serious novel confronts, however, is essentially different from the linguistic emptiness that underlies the grotesquerie of The 
Cyberiad. More committed to representational language, His Master's Voice is also more serious about creating psychologically plausible characterizations. The void here has two loci: the deep vacuum of space, from which the neutrino transmission emerges; and the deep recesses of Peter Hogarth's personality, from which the language that constitutes his narrative emerges. In Hogarth's account as well as in the letter from the stars, the dialectic operates to produce out of a vacuum information so excessive that it finally cannot be distinguished from emptiness. The problem, then, is not how to recuperate ethical judgment from the void, but how to protect it from proliferating significations that threaten to bury it under their excessiveness.

The problem is introduced in Hogarth's "Preface," where he breaks scientific decorum to tell his readers about the dark underside of his public image. Calling his revelations an "antibiography" because they conflict with the beneficent image his official biographers have created (p. I 8), Hogarth asserts that his dominant personality traits are malice, cowardice, and pride (p. 16). The catalyzing event that revealed him to himself was his mother's death, which he witnessed as a child. Seeing her die slowly, agonizingly, he concluded that evil was stronger than good. In that case, his cowardice prompted him to side with maliciousness rather than benevolence. As an adult, Hogarth attempts to construct a personality directly opposite to these innate tendencies and so pardoxically reveals to himself his last innate trait, pride (pp. 6-8).

But then it occurs to him that death may be the work not of evil but of chance: millions of chance accidents, chance misreadings in the cells that accumulate as the years go on. He devotes his talent to proving that chance has played a determining role in human nature. "With the formulae of stochastics I strove to undo the evil spell" (p. Io). Now comes a subtle reversal. So successful is this brilliant mathematician at his chosen task that chance is indeed established as the determining factor in human evolution. Paradoxically, then, chance no longer opposes necessity but becomes necessity. Thus a new rebellion is necessary: "I know that Chance fashioned us, put us together as we are-and what, am I to follow submissively all the directives drawn blindly in that endless lottery?" (p. I 8). If his in- 


\section{I32 Something out of Nothing}

nate personality is the result of chance, Hogarth will seek freedom by fighting against this "endless lottery." Thus he strives to become what he naturally is not-benevolent, brave, humble.

In Hogarth's antibiography, a familiar pattern is at work. ${ }^{10}$ The dialectic circles back on itself so that two opposites, chance and necessity, are enfolded into one another. Whereas in The Cyberiad this circling back caused ethics to emerge, in His Master's Voice it undermines the initial clarity of Hogarth's ethical judgments. For example, what if someone were naturally good? Would it follow that to attain freedom, he should strive to be evil? Though Hogarth poses the question, he is unable to give a satisfactory answer. Once articulated, the dialectic seems to take on a life of its own and will continue to dominate the events not only of Hogarth's life but also of humankind's encounter with the letter from the stars. Ethical judgments that begin by being clear-cut become progressively ambiguous as the dialectic proceeds. ${ }^{.1}$

Already at work in Hogarth's "Preface," the dialectic continues to enfold chance into necessity through the dramatic story of how the "letter" is discovered. Swanson, a physicist who is part guru, part scientist, hits upon the idea of using recordings of cosmic background radiation to generate random number tables. Random numbers are useful in scientific work because the sequences within them manifest no consistent pattern; they may thus be used to simulate chance events. A scientist using the random number tables discovers, however, that sequences in the first volume are repeated in the second. Concluding that Swanson copied his results from the first volume into the second rather than transcribing new radiation recordings, he sues Swanson for fraud. But Swanson has not cheated. Across a narrow band, the neutrino radiation does in fact repeat itself about once every two days. This repetition is all that enables

\footnotetext{
${ }^{10}$ Hogarth's circuitous reasoning in the "Preface" is strikingly parallel to that of Jacques Monod in his Chance and Necessity (1972). Monod's account, like Hogarth's, emphasizes the interplay between chance permutations and genetic replication in the evolutionary process. Published in France a year after His Master's Voice appeared in Poland, Chance and Necessity is unlikely to have been a direct influence on Lem, although Monod's technical articles may well have been part of Lem's reading. In any case, Monod's text provides a context that clarifies Lem's novel.

${ }^{11}$ Edward Balcerzan, I975, makes this point in a different context.
} 
the radiation to be recognized as a message, for it is so densely coded that in all other respects it is virtually indistinguishable from noise. The government turns the investigation of the transmission into a top-secret project- "His Master's Voice."

Despite the best efforts of the project's scientists, they never discover whether the radiation is in fact a letter from the stars, or indeed if it is a message at all. Hogarth sees it as a "particularly complex Rorschach test" in which the scientists "attempt, behind the veil of incomprehensible signs, to discern the presence of what lay, first and foremost, within ourselves" (2:32). First seen as noise, then as signal, the transmission also acts as a mirror, reflecting the systematic misreadings of what Hogarth calls Earth's "predatory" science (13:15I).

Almost alone among the scientists, Hogarth realizes that attempts to interpret the letter can never escape the hermeneutic circle. The reflexive nature of the project becomes apparent when an early decision is made to use binary code. Later Hogarth notices tiny discrepancies in the transmission, so minute that they cannot be translated into binary code. When his fellow scientists argue that the discrepancies represent a slight blurring of the transmission as it travels through space, Hogarth proves that the transmission is accurate to the limits of the recording instruments. The transmission's code, in other words, is not binary. But the scientists continue to act as if it were, thus encoding their own assumptions into the presumed decoding of the letter. Although Hogarth does not dwell on the matter, the incident illustrates how chance enters into the translation and becomes fossilized there as initial hypotheses become unexamined premises. What the scientists see in the transmission, Hogarth more than hints, is what they have projected onto it.

The scientists are doomed to misunderstand because they can never escape their anthropomorphic perspective, encoded not only into the symbol systems but into the very structure of their brains. In that case, the possibility arises that the mistranslations are in some way systematic, not the work of chance but the necessary consequence of human brain structure and evolution. Since this evolution itself originated in chance, however, there exists no possible filter by which the systematic distortions of necessity can be separated from the fortuitous operations of chance, even if one assumes that such a 


\section{I34 Something out of Nothing}

transcendent, nonhuman viewpoint is possible. So Hogarth, and all of the other scientists, are trapped in what he calls "carousellike" reasoning (2:28) in which premises become conclusions and conclusions premises, chance necessity and necessity chance. Beginning with chance, the dialectic moves toward necessity, then circles back to enfold both within the same space.

The dialectic is also at work within Hogarth's interpretation of his antibiography. Does he reveal the secrets of his private life to illuminate his actions in the project? Or does he undertake to write the project's history to indulge in narcissistic self-revelation? Recognizing the possible circularity, he wants to believe that the "ugliness of my malice I made public . . . to divorce myself from it." But suppose that "by stealth, it penetrated, permeated my 'good intentions' and all the time guided my pen. . . In this diametrically opposed view of the matter, what I held to be an unpleasant necessity . . . becomes the primary motive, while the subject itself-His Master's Voice-is a pretext that comes conveniently to hand" $(2: 28)$. In the same way that chance and necessity are enfolded into the same space within the antibiography, so these two texts are further enfolded into each other as pretext becomes text, text pretext. The dialectic that Lem saw "guid[ing his] pen" applies as well to Hogarth and the narrative spaces his writing creates.

The dialectical circularity of the novel is reinforced by its posthumous status. Because Hogarth dies before his book is published, it is the editor, Thomas Warren, who decides that the antibiography will serve as preface rather than as epilogue to Hogarth's account. The arrangement implies, of course, that the scientific work grows out of Hogarth's interpretation of his life. A note from Warren explaining why he chose to put the antibiography first makes us aware, however, that the book could just as easily have been assembled the other way around. Is the order of the text finally determined by necessity or by chance? We have no way to know, since both text and pre-text have already been caught up in a circular dialectic that makes it impossible to establish which came first.

The dialectic circles endlessly because at the center of the text is a permanent engima: the neutrino radiation. As long as the transmission remains incomprehensible, neither Hogarth nor anyone else can close the narrative space by showing which of the data fore- 
shadowed the known end. The transmission thus acts like a hole puncturing the textual enclosure of the novel. Painfully aware of the openness that this enigma introduces into his text, Hogarth attempts to compensate by including as much as possible within his narrative. "I do not know what it is among the people of the Project that determined finally the Project's fate," he admits. "Therefore, just in case, thinking of the future, I am also presenting here those bits and pieces that I have not been able to put into any coherent whole. Perhaps someone else, someday, will manage that" (4:57). The hope is illusory, for as Hogarth himself acknowledges in his attempts to decode the letter, it is impossible ever to describe anything completely. Any description presupposes a frame of reference that limits, even as it creates, what is said.

The hope that a definitive reading may one day be possible, illusory though it is, impels Hogarth to write his antibiography and to include in his account personal, often unflattering portraits of his colleagues. How to locate in this complex space the relation between cause and effect which readers ever since Artistotle have demanded of fictions? $?^{12}$ The difficulty is not merely that Aristotelian assumptions of unity do not apply. They also do not necessarily not apply, for it may be that most, or even all, of the data are relevant. But we have no way to know. Because the transmission remains an enigma, it is impossible to read the text teleologically and consequently impossible to distinguish chance events from necessary outcomes. ${ }^{13}$ There is no possibility for a definitive interpretation of the text, whether the text is conceived as the neutrino transmission, Hogarth's antibiography, Hogarth's account of the project, Thomas Warren's edited text of Hogarth's accounts, or the entirety that is Stanislaw Lem's novel.

Against this background of pervasive uncertainty, a few known quantities do emerge. Hogarth's first and, as it turns out, only contribution toward decoding the transmission is to demonstrate that it possesses a mathematically closed structure. It closes "like an object separated from the rest of the world, or like a circular process,"

\footnotetext{
${ }^{12}$ For an example of a puzzled response to this lack of unity, see Peter S. Beagle, I983.

${ }^{13}$ Monod discusses teleonomy in an argument that sets forth in biological terms the same problems that Hogarth faces in shaping his text (1972:3-44).
} 


\section{I36 Something out of Nothing}

Hogarth says, then adds, "to be more precise, like the DESCRIPTION, the MODEL of such a thing" (6:86). It is possible to hear in Hogarth's language a nostalgic yearning for a lost world of unproblematic referentiality. By establishing that the letter possesses formal properties of closure, Hogarth has indeed limited what it can be. He succeeds in proving that it is a "description of a phenomenon" (6:88). But when the research teams assign stereochemical meanings to the transmission's symbols, the text is inevitably opened again to chance.

From these assigned meanings the scientists are able to construct a physical substance. Whether this substance is what the letter was meant to describe remains problematic, however, since there is no way to be certain that the assigned meanings correlate with the letter's symbols. The substance may be a correct materialization, or a garbled distortion that reflects only the anthropomorphic biases of its creators. The ambiguity is reinforced by the uncertain purposes to which the substance might be put. Is it a miracle compound, revealing secrets hitherto unknown to terrestrial science? Or is it a first step in the Senders' plan to take over the planet? The ambiguity is encoded in the names the scientists choose for the substance. The biophysicists call it "frog eggs"; the biologists, "Lord of the Flies." Whether the substance is a tool for creation or destruction is as uncertain as whether it is the product of chance or design.

A third known quantity emerges from the letter's form, when it is discovered that the radiation composing the transmission has precisely the right range of frequencies to affect favorably the development of large protein molecules. If it had been present when Earth was young, it would have significantly increased the chances that life would evolve. It is, in other words, biophilic. Arguing from premises familiar to literary critics, Hogarth believes that since the form of the letter is conducive to life, the content must also be benevolent. He therefore pooh-poohs the notion that the letter may be intended for evil purposes, that it may, for example, describe a life form that will take over the planet as soon as it has materialized. In the absence of any context for the letter, however, Hogarth admits that his belief in the essential goodness of the Senders is faith, not fact. Although there is thus something that can be said about the letter, some facts and tangible products have been derived from it, its meaning remains ambiguous. 
From this uncertainty comes Hogarth's severest test of faith. The occasion arises when Hogarth's friend and colleague Donald Prothero thinks of subjecting "frog eggs" to the same neutrino wave of which it is a materialization. Thus the transmission is turned back on itself, in a circular dialectic reminiscent of the circles-within-circles that are recurrent structures in the novel. This reflexivity suggests that the experiment will be crucial, and it is. The irradiation of "frog eggs" with the neutrino wave unleashes an awesome energy that, if projected on a suitably large scale, could turn into a doomsday weapon.

With this discovery, the ethical ambiguities implicit in Hogarth's account reach their height. A peace advocate, Hogarth has been suspicious from the start of the Pentagon's role in the project. His suspicion has been reinforced by the physical restrictions placed on the project's personnel. When Hogarth joined the project, he perforce also entered the secret desert compound that housed it. The psychological distaste he feels for the project's secrecy is manifest in his claustrophobic physical response to the enclosed compound. But now he and Prothero find themselves compelled to form a conspiratorial circle within this larger circle of secrecy, for they know that it is only a matter of time before someone else also discovers that the substance can be used to create explosions. As the circles-withincircles tighten into increasingly oppressive enclosures, the conspirators are put in the position of doing exactly what they most fear others will do-developing the weapon. Their panic about the implications of what they have discovered makes them desperate to find some way to gain control over the situation. Hogarth fleetingly entertains the idea of declaring himself dictator of the planet, using the weapon to force peace on humanity. He quickly realizes, however, that such a paradoxical venture would lead only to further oppression and to an even more claustrophobic enclosure.

The essence of the trap within which Hogarth finds himself caught is a context so coercive that it completely determines action, regardless of individual motives or beliefs. Hogarth has been darkly imagining that the Pentagon is funding the project because it hopes that a weapon will emerge. There is a fine moment when someone suggests to him that the Pentagon is involved because it is afraid a weapon may emerge and cannot take the chance that it may not be under its control. Thus the Pentagon, like Hogarth and Prothero, is shown to 


\section{${ }_{13} 8$ Something out of Nothing}

be the victim of a coercive context that forces it toward global annihilation, regardless of what its leaders may or may not want to do.

From such subtleties, the picture slowly emerges of an entire society caught up in a coercive context that determines how its texts will be read. When Prothero writes to government officials insisting that information about the project should be shared with the Russians and proposing that the two nations should work together to crack the code, his letter serves only to identify him as an object of suspicion. The militarists refuse to consider his plan because they are convinced that the Russians would only pretend to cooperate, meanwhile setting up a second, real team in secret. Prothero is outraged by this answer. Its probability is indirectly confirmed, however, when Hogarth discovers that this is exactly what the Pentagon has done with them. He learns that there is not one project, but two. "His Master's Voice" is shadowed by a second, even more secret project, appropriately named "His Master's Ghost" (I3:I 53). The doubling, with its suggestion of self-reflexivity, emphasizes that the human text performs as if it were void, emptied of content, when it is enclosed within a sufficiently coercive context.

For Hogarth, being trapped within a context that seems inevitably to be leading him and everyone else toward global destruction is the nadir of experience. It is the nightmare of his mother's death, returned and magnified. In a long, drunken wake for humanity, he and a confidante try to imagine what accidents of fate, what chance events were fossilized into the history of the race to cause the present context to emerge. In his antibiography, Hogarth first saw chance as a way to fight evil, then concluded that chance and necessity were inextricable. At this moment, chance becomes for Hogarth evil as well as necessary. The dialectic has become a vicious circle.

The way up and out is characteristically a further inversion of, rather than a retreat from, this conclusion. Unable to escape its coercive context, humanity is delivered by what Hogarth interprets as a triumph of text over context. When the future seems darkest, Prothero discovers that the explosion's accuracy diminishes with range, so that it is worthless as a weapon. Hogarth comes to believe that only the mistranslations of earth's "predatory" science made the weapon even seem possible. The weapon fails to work, he believes, because the Senders were able to create a tamperproof text, a mes- 
sage so immune to misinterpretation that not even the coercive context of global war could empty it of its benevolent content. Just as the threat of the doomsday weapon enacted on a magnified scale Hogarth's first personal encounter with death, so the Senders' text achieves on a cosmic scale the solution Hogarth sought when he dedicated his life to the study of chance. The Senders deliver humanity from impending annihilation because they have mastered chance.

Are we to endorse this conclusion? As Hogarth admits, it is not necessarily true. Other explanations are possible. It remains for Hogarth an act of faith, a belief that ethics can be recuperated because chance can be controlled. But then Hogarth places the control of chance at the center of his own life as well, so his conclusions about the neutrino transmission are suspiciously parallel to his conclusions about his life. It is clear that for Lem, the answer is more complex than Hogarth, in his optimistic conclusion, wants to believe, for the ambiguities that Hogarth overcomes by an act of faith are reinforced as the novel draws to a close.

The final pages recount what happens when scientists from "His Master's Ghost" arrive to present their interpretations of the neutrino transmission. Whereas researchers from "His Master's Voice" have been assuming that the neutrino wave is a letter that implies Senders, those from "His Master's Ghost" have been working on the assumption that the transmission is a message that has form but no content, or a message that has no sender. These alternative possibilities undermine the reader's faith, if not Hogarth's, that humanity is saved because the Senders can control chance. There may be a voice, or there may be only a ghost. Ethics may emerge from the void, or it may not. Moreover, the reflexive mirroring between each project's name and its conclusions (the Voice project believes there is a sender, the Ghost project that there is not) reinforces the suspicion that each project reads itself in the message rather than decodes whatever is actually there.

These self-reflexive mirrorings and the uncertainties they engender are necessary to make sure that the textual space can never be definitively closed. For if the Senders were able to control chance, might not the cosmos itself someday become an oppressive enclosure? Only because the transmission remains enigmatic can the universe be open to both chaos and order, chance and necessity. Only 


\section{40 Something out of Nothing}

because a hole gapes within the center of the text can the necessity to cease writing be enfolded together with the ongoingness of creation. For Lem, the encounter with chaos is less a celebration than an ambiguous necessity.

The dialectical enfolding of chaos into order serves both as the mark of Lem's affinity with his time and as the stamp of his individuality. In his concern with chaos and with textual dissemination, Lem has strong affinities with the new paradigms. Yet in his insistence on rational consistency and rigorous extrapolation from known facts, he can also be seen as very much at odds with the postmodern temper. To place him at either of these extremes is in an important sense not to see him at all, for it is from the tension between these polarities that his writing emerges. He is on the cusp of the transition from the old to the new paradigms but not actually within either, for he resists the synthesis the new paradigms offer at the same time that he exposes contradictions that the old did not recognize. His work testifies that during a paradigm shift, change arrives not by a single sweeping transformation but by complex compromises negotiated at specific sites.

Lem's contribution to the twentieth century's encounter with chaos is to reveal (perhaps inadvertently) an ambiguity within chaos theory which has not received the attention it deserves. As I remarked earlier, chaos theory has a double edge, at once celebrating chaos's resistance to rationalization and striving to overcome this resistance. Lem uses a similar opposition as the basis for his craft. In this respect he has fully come to terms with an ambiguity that most chaologists are only beginning to think about. His distinctive achievement is to use the tension between chaos and order to create a space for writing that cannot be enclosed even within its own selferasing confines. We may trace where the dialectic has been by following the motion of the pen; but the dialectic itself is never written, always writing. ... 